\title{
Do gesto à notação: exemplos de escrita prescritiva em duas obras contemporâneas
}

\section{Danilo Bogo \\ Cristiano R. Galli}

Resumo: O presente artigo discute o conceito de gesto musical e sua transformação em notação. De início são apresentados três conceitos relacionados ao gesto musical - gesto físico, gesto mental e gesto notado -, em seguida são discutidas suas relações com a composição, a notação e a performance. $\mathrm{Na}$ terceira parte do texto, são demonstradas formas prescritivas e descritivas de notação do gesto observadas em duas peças compostas pelos autores. Por fim, são propostas duas formas de notação prescritiva para um mesmo recurso encontrado no software SuperCollider chamado Theremin. Nesse recurso as diferentes posições possíveis da seta do mouse na tela do computador definem o resultado da síntese gerada pelo software.

Palavras-chave: Gesto musical. Notação. Eletrônica mista. Escrita para mouse.

From gesture to notation: Examples of prescriptive writing in two contemporary works

Abstract: This article discusses the concept of musical gesture and its transformation into notation. We first introduce three concepts related to musical gesture - physical gesture, mental gesture, and notated gesture - and subsequently explore how they relate to composition, notation, and performance. Thirdly, we demonstrate prescriptive and descriptive types of notation observed in two pieces composed by the authors. Finally, we propose two forms of prescriptive notation for a single tool found in the SuperCollider software, Theremin. In this tool, different possible positions of the mouse arrow on the computer screen define the result of the synthesis generated by the software.

Keywords: Musical gesture. Notation. Mixed music. Mouse writing. 
Neste artigo trabalharemos primeiramente o conceito de gesto musical e sua relação entre compositor, intérprete e notação. Em seguida abordaremos a realização escrita do gesto (ou gesto notado) em duas obras compostas pelos autores deste artigo.

A definição de "gesto musical" revela-se, por vezes, controversa dependendo da perspectiva escolhida para abordagem do tema que na essência pode ser a do compositor ou a do intérprete. Gesto é movimento com uma intenção específica (FORNARI, 2012), ou, na perspectiva de Hatten, uma "configuração energética de expressividade significativa realizada no tempo ao longo de todas as modalidades de percepção, ação e cognição"1 (2004, p. 97). Assim, segundo Kululuka (2001), "cada gesto reflete uma atitude ou um movimento estável instigador de uma intuição e revelador de uma lógica da real necessidade de expressão de uma ideia (intenção gestual), de um fato ou de uma ação (ação gestual)2" (p. 4). Zagonel (1992), fazendo eco às ideias de Kululuka, propõe uma interessante perspectiva apontando para a existência de dois tipos de gestos sendo o primeiro gesto físico e o segundo gesto mental. Por gesto físico a autora entende "a ação corporal que, em contato com um objeto, provoca uma reação sonora" (p. 15). Essa seria a forma mais "visível" de um gesto, uma ação no espaço e no tempo apreendida pelos sentidos da visão e que de certa forma gera a expectativa sonora a ser concretizada. Portanto essa primeira manifestação física estaria, por assim dizer, em um primeiro plano na comunicação. Já por gesto mental, a autora o define como aquele que "se produz no pensamento, está sempre presente no músico enquanto compositor ou intérprete" (p. 17). Essa forma de gesto que antecede o gesto físico - está portanto na base, na gênese do

\footnotetext{
1 "expressively significant, energetic, temporal shaping across all human modalities of perception, action, and cognition". Todas as traduções foram realizadas pelos autores.

2 "chaque geste reflète une attitude ou un mouvement stable, instigateur d'une intuition et révélateur d'une logique du réel nécessaire à l'expression d'une idée (geste propositionnel), d'un fait ou d'une action (geste actionnel)".
} 
resultado sonoro, como elemento primordial, do qual será o gerador das ocorrências no plano físico ou que irão gerar os gestos físicos. Esse tipo de gesto se encontra tanto na imaginação do intérprete quanto na do compositor.

Na perspectiva do intérprete o gesto está presente quando, este, ao ler uma obra escrita, desde o início, constrói mentalmente os caminhos gestuais aos quais em seguida irá percorrer para atingir seu intento, que por fim é a concretização do gesto mental em gesto físico para a manifestação da obra no plano da escuta. Assim sendo, compartilhada a partir da ação gestual, a mensagem contida na obra é concretizada pela ação no plano físico comunicando o conteúdo aos demais ouvintes.

Já para o compositor, o gesto está, muitas vezes, na gênese criativa. Dessa forma, o gesto vive na mente do compositor e é transmitido como informação ${ }^{3}$ a priori para, posteriormente, tornar-se gestual-físico pelo intérprete. Muita discussão poderia ser motivada por essa perspectiva tal como a função cocriadora do intérprete ou qual a legitimidade do gesto mental do compositor como autoridade na obra. Essas questões - mesmo que relevantes - fogem ao escopo deste texto e poderão ser desenvolvidas em outra oportunidade.

A ideia de gesto musical vem tomando cada vez mais espaço nas discussões atuais. O presente artigo é, em parte, fruto das discussões e apresentações de trabalho que tiveram lugar no seminário de Análise para Intérpretes III, cujos módulos, ministrados pela Prof. ${ }^{a}$ Dr. ${ }^{a}$ Zélia Chueke, em agosto de 2017, no âmbito do Programa de Pós-Graduação em Música da UFPR, foram dedicados ao tema do "Gesto Musical-Gesto de Execução".

\footnotetext{
3 É importante salientar que o termo "informação" aqui citado diz respeito não somente a partitura em si, mas também às informações históricas, estilísticas, composicionais que podem ser recolhidas sobre uma obra em questão. Quando executamos uma obra do período barroco, por exemplo, associamos uma série de atitudes gestuais que não estão necessariamente contidas na partitura, mas que foram recriadas segunda uma concepção historicamente informada. Dessa forma, a simples descrição de uma obra pelo compositor ou a citação de sua fonte de inspiração pode influenciar a atitude gestual do intérprete.
} 
Essa discussão se inicia, segundo Souza (2004, p. 2), por conta de uma crise que surge na concepção que buscou a serialização de todos os parâmetros de uma obra musical. Essa abordagem foi conhecida como serialismo integral, sendo Pierre Boulez um de seus maiores expoentes. Nessa abordagem não só o parâmetro das alturas deveria seguir uma ordem pré-estabelecida, como também os parâmetros de intensidade e ritmo. Dessa forma, o gesto musical passa a estar subordinado a fatores pré-estabelecidos pela serialização; o resultado dessa organização surgirá no discurso como resultado do processo e não como elemento a priori concebido. A concepção de gesto, por outro lado, "reúne combinações paramétricas que o organizam enquanto conjunto expressivo" (ibidem), isto é, no gesto os parâmetros "agem e interagem como partes de uma unidade orgânica" (ibidem). Dessa forma, o gesto reúne em si os parâmetros de altura, intensidade, timbre, expressão etc. num todo indissociável.

\section{Do gesto à escrita}

A passagem do gesto mental do compositor ao gesto físico do intérprete é mediada pela escrita. Segundo Marie (1973), a escrita musical veio do gesto (chironomy) 4 que permitia ao regente de coro relembrar aos cantores as linhas melódicas. Assim, posteriormente, a linha desenhada pela mão se tornaria gráfica (p. 42-3). Carvalho (2005) - citando Adorno a propósito da notação - sustenta que os signos musicais seriam "imagens de gestos" que teriam surgido para fixar a "práxis mimética" quando esta já começava a desaparecer (p. 212).

O gesto musical pode ser visto, nesse contexto, como o elemento primordial que contém em si o conteúdo estético sonoro, isto é, o

\footnotetext{
${ }^{4}$ Um método de dirigir o canto gregoriano por gestos das mãos indicando o subir e descer de uma melodia. Disponível em <https://www.merriamwebster.com/dictionary/chironomy>. Acesso em 8 de dezembro de 2017.
} 
elemento abstrato que está no que poderíamos dizer em estado potencial, já que carrega como que um pacote de informações a serem manifestadas no momento da realização concreta. Assim, entendendo a manifestação do gesto no mundo físico se torna necessária - para a transmissão ou mesmo o registro desse elemento para além da memória - uma plataforma a qual se possa registrar esse conteúdo. Podemos dizer então que nesse momento encontramos a grafia musical como forma de registro, porém é possível observar que o registro gráfico em si não define de imediato o gesto de execução mas sugere, ou melhor dizendo, fornece instrução para a manifestação desse. Assim, partindo dos termos "gesto mental" e "gesto físico" propostos por Zagonel (1992), adicionaremos o conceito de "gesto notado" entendido aqui como a representação gráfica do gesto.

Sobre o gesto notado, Wishart (1996) coloca que a estrutura gestual é o mais imediato aspecto da comunicação musical, já a notação, por outro lado, está sujeita à interpretação o que torna a relação entre gesto e notação de certa forma problemática (p. 17 e 18). Apesar da dificuldade em notar o gesto musical, a partitura (ao menos no caso da música de concerto) apresenta-se como o elemento mais significativo de comunicação entre compositor e intérprete, e é, muitas vezes, o único documento que acessamos para interpretar uma obra.

Em "Notação, Representação e Composição", Zampronha (2000) defende que partitura e performance são coisas distintas, partitura não é a obra em si, mas a codificação de um ideal escrito no papel que pode levar a performances diversas (p. 22-3). Apesar das diferentes performances que podem surgir de uma mesma partitura, há, ainda latente, esse ideal supracitado, essa essência que nos faz reconhecer a mesma música nessas performances distintas (p. 23-4). Por ideal entendemos, obviamente, o que é possível notar no nosso sistema ortocrônico ${ }^{5}$ que possui suas imperfeições. Nos expressamos por meio

\footnotetext{
5 Introduzido por Gardner Read (1979, p. 23-4) "este conceito derivado de orto = correto, certo e chrónos $=$ tempo, define a correspondência que facilita a
} 
desse sistema, assim a notação, por outro lado, influencia na forma de compor quando temos de nos expressar pelos únicos estereótipos que ela permite. Dessa forma, mesmo não sendo música, a notação influencia a forma como fazemos música, assim fica difícil considerá-la como um objeto "neutro" entre o pensamento do compositor e a performance (ZAMPRONHA, 2000, p. 118-22).

\section{O gesto nas obras}

A seguir trataremos da problemática do gesto notado em duas obras específicas. Duas peças eletrônicas-mistas que foram encomendas pelo coletivo Contackte do qual os autores deste artigo são compositores/integrantes. As obras compostas foram executadas pelos membros do grupo e podem ser acessadas na plataforma YouTube ${ }^{6}$.

O Coletivo Contackte surgiu em 2016 como uma plataforma de fomento de arte contemporânea tendo como objetivo a colaboração entre diversas áreas artísticas/tecnológicas como música, artes visuais, informática, dança etc., cujos membros detêm conhecimento em ao menos uma das áreas específicas.

A problemática do gesto esteve presente durante a elaboração das obras Contacktus e Uma cor que desentorte o arco-íris. Cada obra apresenta uma perspectiva própria para lidar com essa problemática que em ambas está ligada a como tornar o gesto mental - emprestando do termo utilizado por Zagonel (1992, p. 17) que em suma representa um elemento potencialmente imaginado pelo compositor - em gesto notado, ou seja, a representação gráfica que será interpretada pelo performer e

compreensão de altura e duração, sincronicamente, com a clareza individual e a concisão característica para cada símbolo no espaço da partitura, facilitando a performance e a memorização" (BAIRRAL, 2010, p. 122).

${ }^{6}$ Contacktus - Cristiano Galli: https://www.youtube.com/watch?v=3idON0gCqN8.

Uma Cor que Desentorte o Arco Íris - Danilo Bogo: https://www.youtube.com/watch?v=ev81E78A9W4\&t=17s (acesso em 26 de dezembro de 2017). 
posteriormente transformada em som (gesto físico). A problemática tratada neste artigo evoca não a elaboração do gesto ou mesmo a preocupação da manifestação desse no mundo físico, mas sim a relação compositor-intérprete. Essa conexão deve ser mediada então por uma plataforma gráfica, nesse caso ambas as obras empregam a grafia tanto descritiva quanto prescritiva?.

Fez-se necessária a ambas as obras o desenvolvimento de uma grafia própria a qual pudesse representar de forma mais clara e objetiva os gestos mentais propostos. Isso se deu devido à natureza não convencional desses gestos e também ao emprego da eletrônica que, por si só, gera demandas outras as quais a grafia convencional não contempla. Sendo assim, ambas as composições trataram de propor soluções para essa problemática, cada qual desenvolvendo sistemas distintos devido às características de cada obra. "Contacktus" trabalha com a figura do regente, entendendo-o como um elemento-chave na construção do discurso musical; por outro lado "Uma cor que desentorte o arco íris" não trabalha com regência, mas sim com a escrita proporcional na qual a unidade está registrada por segundo; a ausência da regência exige ainda mais atenção à grafia e ao gesto notado.

\section{Contacktus}

Obra escrita em 2016 para piano, percussão, eletrônica I (Diferida) ${ }^{8}$, eletrônica II (em tempo real - live eletronics) e regência. A difusão da eletrônica é operada por apenas um intérprete, possibilitando

\footnotetext{
7 Para Segger (1997 apud Zampronha, 2000), na notação prescritiva o compositor diz ao intérprete quais ações ele deve tomar para chegar em um resultado desejado (uma tablatura, por exemplo); já na descritiva o compositor diz o resultado desejado sem indicar ao intérprete como proceder para o conseguir (ex.: escrita ortocrônica sem digitação).

8 Termo empregado para designar a eletrônica pré-gravada e sons eletroacústicos fixados em suporte.
} 
a execução por quatro integrantes. Com duração de cerca de oito minutos, a peça utiliza escrita "proporcional" 9 com o auxílio de minutagem, que aponta para o momento aproximado em que devem ser introduzidos os eventos. Dividida em 16 sessões, explora as relações tímbricas entre as fontes sonoras eletrônicas e acústicas, ora promovendo uma fusão por saturação dos elementos "fusão por meio da similaridade textural" 10 , ora criando texturas a partir dos elementos difusos em planos sonoros distintos "contraste por distinção textural"11. A obra também possui uma projeção visual criada pelo cineasta Manuel Reva, que deve ser projetada sobre os intérpretes com a finalidade de trazer à obra uma dimensão imagética que colabora na construção estética e discursiva da peça.

No transcorrer do processo de composição algumas problemáticas surgiram. Logo de início, deparamo-nos com a necessidade de uma definição da tipologia da escrita. Uma vez que a escrita convencional não nos pareceu suficiente para abarcar todos os elementos com os quais a obra trabalha, optamos pela escrita proporcional com minutagem aproximada como plataforma básica. Isso posto, para a notação dos gestos foi utilizada tanto a grafia prescritiva quanto descritiva, dependendo da natureza e conteúdo gestual e como este se manifesta na obra.

Para gestos cujo conteúdo é composto por notas de alturas definidas, empregamos então a chamada escrita descritiva a qual "descreve" (principalmente para o instrumentista) o resultado sonoro a ser atingido. Segundo Zampronha (2000, p. 48), essa escrita dá-se de forma bidimensional e é construída sobre dois eixos: um sendo vertical, no qual

${ }^{9}$ A organização temporal é aproximada, sendo indicada por intermédio da posição relativa dos eventos musicais - células rítmicas e motívicas, por exemplo - nas diferentes vozes e instrumentos (MORGAN, 1992, p. 410).

10 Anulação de uma distinção categórica do que é instrumental e do que é eletroacústico (MIRANDA; BARREIRO, 2011, p. 9).

11 Os dois universos estão presentes e em total divergência (ibidem). 
se regista a altura (agudo/grave), e outro horizontal, no qual a duração de um som ou mesmo do silêncio é mensurada.

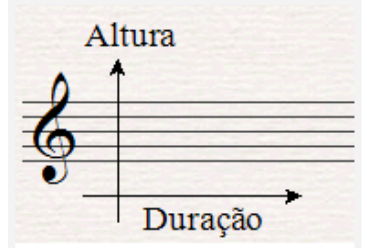

Fig. 1

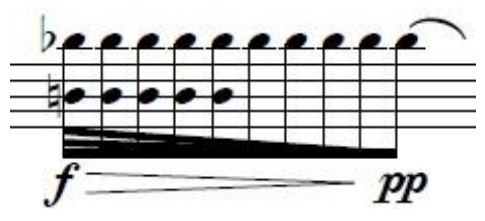

Fig. 2: (sessão 16 - vídeo 7:2412)

A figura 1 demonstra a bidimensionalidade que caracteriza a escrita descritiva em seus dois eixos de altura e duração. Na figura 2 podemos observar o emprego dessa escrita para o registro gráfico do gesto musical, que em seu conteúdo é composto por altura definida e em sua dimensão temporal possui um desacelerando.

Para os gestos ao quais o eixo bidimensional não se aplica de forma satisfatória, foi empregada a escrita prescritiva.

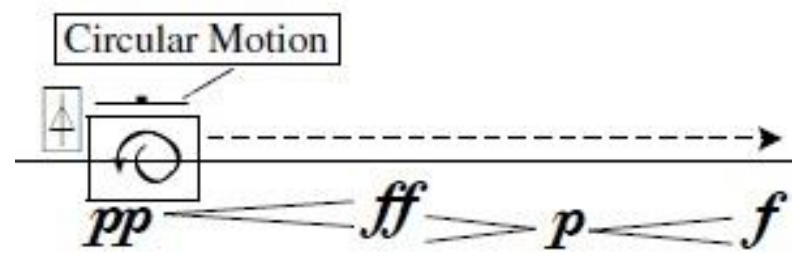

Fig. 3: (sessão 2 - vídeo 1:10)

12 O primeiro número (sessão $X$ ) representa a sessão que aparece anotada na partitura (equivalente a uma espécie de hiper-compasso). O segundo número (video $X: X)$ representa a minutagem onde o excerto pode ser escutado no YouTube. As partituras de ambas obras podem ser baixadas no: https://drive.google.com/open?id=1_4VskC5zakS4DdOF2YX5KTaZpgAe-h9_ (acesso em 20 de março de 2018). 
$\mathrm{Na}$ figura 3 podemos observar um exemplo de escrita em que consideramos a "prescrição" como sendo a forma mais adequada para o registro gráfico do gesto musical em questão, gesto este que contém um movimento circular sobre um prato descrito textualmente e reforçado pela figura logo abaixo do texto. A velocidade do movimento não está definida, dando ao performer a liberdade de interpretação.

$\mathrm{Na}$ obra em questão a regência tem função fundamental, pois as seções possuem uma duração temporal registrada em segundos aproximados representados na forma de "ñ". Este fator de inexatidão temporal confere ao regente um papel distinto do convencional e uma ação fundamental na performance, pois cabe a esse a determinação temporal exata para a realização dos eventos; basicamente, o regente indica onde um som deve começar e terminar diferentemente da função tradicional da regência em que o regente, por assim dizer, reforça ao performer o momento de ação em um tempo já registrado na partitura. Em Contackus este tem certa liberdade em definir a exata manifestação dos gestos notados na pauta.

A figura a seguir apresenta uma das sessões (S. 9). Nela podemos visualizar os gestos notados prescritivos realizados pela percussão, bem como os gestos notados descritivos que aparecem no piano. Na Eletrônica II há uma sobreposição de síntese que resulta em adensamento da textura por meio do que poderíamos chamar de empilhamento, indicada na partitura por "Add" (adicionar). Tornou-se então necessário o emprego de um gestual para regência que indicasse a sobreposição da síntese, optamos por utilizar o movimento que representa a letra "J" na Língua brasileira de sinais (Libras), porém atribuindo a este movimento significado diverso, que nesse caso está em indicar ao performer difusor o momento exato para o adensamento da síntese por sobreposição. É importante salientar que apenas dois integrantes do Coletivo têm formação musical e que essa técnica gestual da regência (como uma 
espécie de soundpainting ${ }^{13}$ ) pôde possibilitar que pessoas que não leem música participem de uma criação musical de maneira ativa, isto é, controlando a eletrônica, realizando gestos básicos em instrumentos musicais etc.

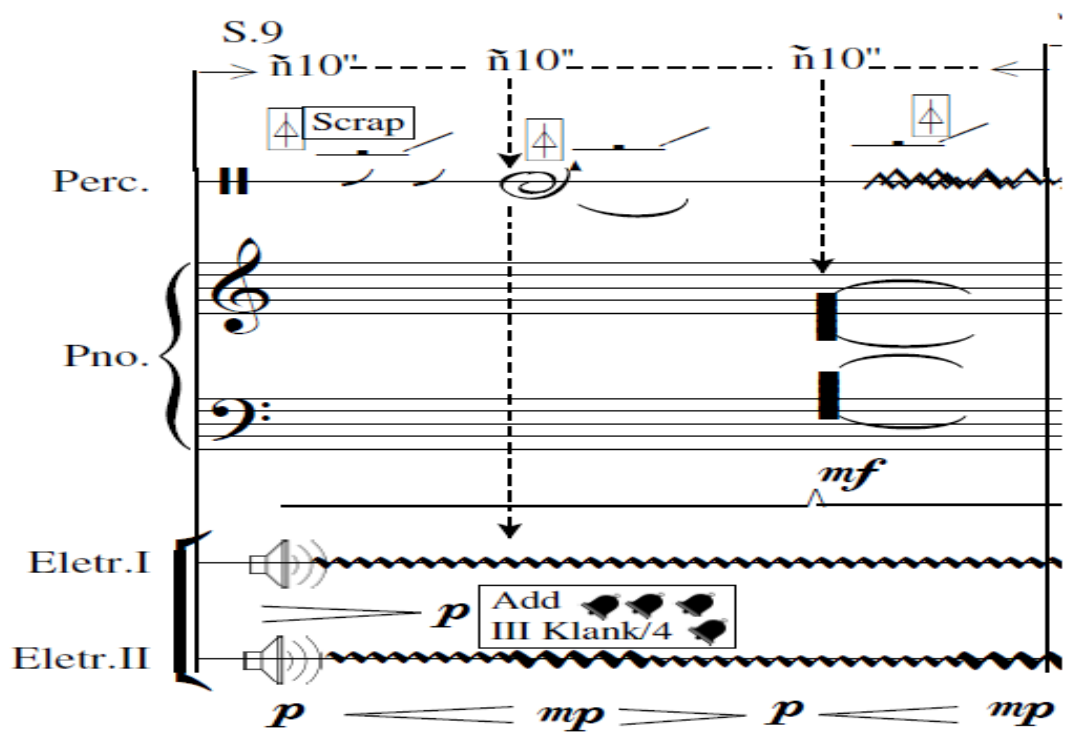

Fig. 4: (sessão 9 - vídeo 3:43)

Solucionada a questão, que diz respeito à notação geral da obra bem como à representação gráfica dos gestos específicos (prescritivos e descritivos), deparamo-nos com a problemática ligada à representação gráfica dos gestos musicais da eletrônica. Essa questão diz respeito, mais especificamente, ao emprego na obra de um recurso chamado Theremim ${ }^{14}$

\footnotetext{
13 Linguagem de sinais gestuais criado pelo compositor Walter Thompson em 1974 que possibilita a composição/improvisação em tempo real. Nesse sistema, que possui mais de 1500 gestos, um regente pode controlar por meio de sinais atores, artistas visuais, dançarinos e músicos (sem necessidade de partitura). (encontrado em http://www.soundpainting.com/soundpainting/ acesso em 26 de dezembro de 2017).

$14 \mathrm{O}$ termo Theremin aqui se refere ao recurso disponível no software SuperCollider no qual é possível intervir na eletrônica em tempo real através dos movimentos do mouse de um computador. O termo faz alusão ao instrumento criado pelo inventor russo Léon Theremin em 1928.
} 
encontrado no software SuperCollider. Esse recurso permite a manipulação da síntese sonora por meio do movimento realizado com o mouse de um computador que, ao ser direcionado para uma posição específica da tela, interage com o software gerando então alterações na síntese que podem oscilar entre variações tímbricas, de altura ou mesmo de texturas (dependendo da programação).

Nesse caso, a dificuldade consiste em como representar graficamente os movimentos aos quais o performer difusor deveria realizar empregando o mouse. Para solucionar a questão empregamos uma adaptação do plano cartesiano (figura 5) ${ }^{15}$ para o mapeamento dos movimentos tanto da regência quanto dos movimentos que o difusor realizaria. Para regência então ficou estipulado que a mão direita do regente atua em um plano cartesiano imaginário e assim segue representando os valores atribuídos aos eixos " $x$ " e " $y$ ", tal como se realizasse um desenho em uma superfície como uma lousa. Esses movimentos são seguidos pelo difusor utilizando o mouse. Já a mão esquerda mantém a função de representar as dinâmicas. Um fator relevante diz respeito ao agente que determina a ação e que, portanto, define a exata manifestação dos gestos musicais; essa atribuição, nessa peça, está a cargo do regente, mesmo quando a partitura indica improvisação na eletrônica II, como no caso da sessão 9 - vídeo 4:22. A condução dessa improvisação é realizada pelo regente.

15 Sistema de Coordenadas Cartesianas, ou Plano Cartesiano, criado por René Descartes com o objetivo de localizar pontos. Formado por dois eixos perpendiculares: um horizontal e outro vertical que se cruzam na origem das coordenadas. O eixo horizontal é chamado de abscissa $(x)$ e o vertical de ordenada (y). Os eixos são enumerados compreendendo o conjunto dos números reais. 


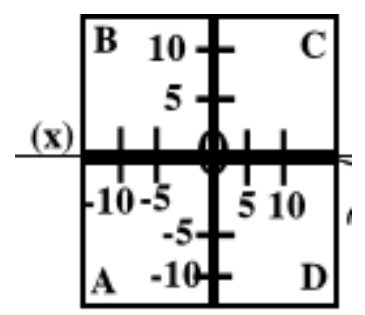

(y)

Fig. 5.

Na figura 6 podemos observar esse modelo então aplicado à pauta musical correspondente a eletrônica II. A linha sinuosa desenha o itinerário pelo qual o dispositivo deve percorrer.

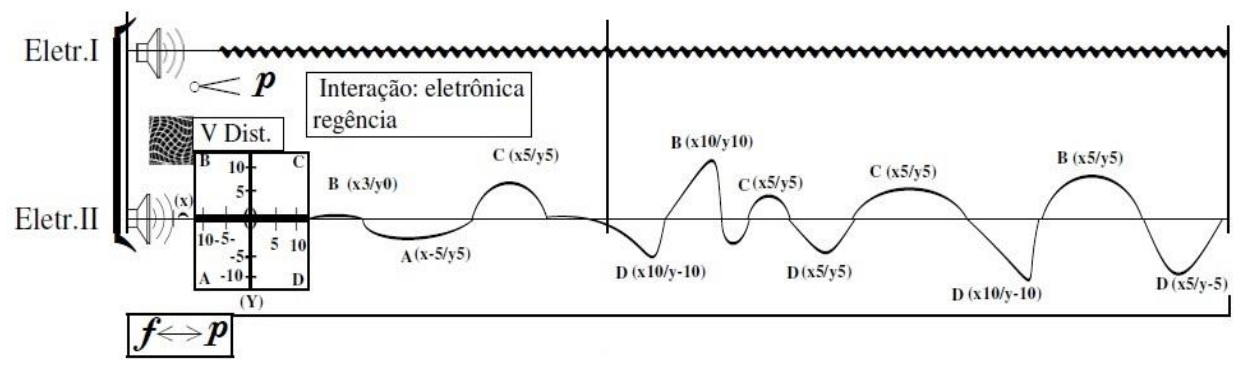

Fig. 6: (sessão 13 - vídeo 5:55)

\section{Uma cor que desentorte o arco-íris}

Com duração de aproximadamente 6' 30 " a peça foi escrita em 2017 para piano e eletrônica, tendo a proporção áurea - e suas ramificações como a sequência Fibonacci - como inspiração para a organização da harmonia e da forma - esta última se apresenta como um ABCBA. O piano assume um caráter solista e a eletrônica - operada por dois intérpretes em dois computadores - mistura sons fixados (eletrônica diferida - escritos em língua portuguesa na partitura) e síntese gerada pelo software SuperCollider (/ive electronics - escritos em inglês) em ambos os computadores. Os sons fixados (pássaros, avião, chuva etc.) são misturados em tempo real pelos dois intérpretes com o auxílio de um 
mixer enquanto os live eletronics (síntese) são controlados pelo mouse e enviados também ao mixer. Os elementos do piano são tratados como objetos sonoros ${ }^{16}$ que se adensam pouco a pouco até atingir dois climaxes pré-estabelecidos pela sequência Fibonacci (fim da sessão A: 89" - vídeo 2:14; e fim da sessão C: $233^{\prime \prime}$ - vídeo 4:38)17. Buscando uma interpretação um pouco mais livre do ritmo escolhemos a escrita proporcional balizada por pequenos traços que representam a medida de um segundo. Assim, o ataque de cada nota é definido pela sua posição aproximada dentro de um segundo dado. Já a duração, no caso do piano, é controlada pelo pedal de sustain, eliminando assim a necessidade de utilização das figuras rítmicas tradicionais. Na figura 7 podemos observar um gesto percussivo no registro mais agudo do piano que é realizado tocando as teclas com a palma da mão e dedos (comparado a um movimento de alguém que toque um bongô, por exemplo). Observa-se também uma aceleração gradativa do gesto (ou adensamento), ao mesmo tempo que as balizas de segundo continuam estáticas, isto é, do mesmo tamanho. Como não há figura de tempo, decidimos usar os clusters em preto para as teclas pretas e os brancos para as brancas. Na figura 7 observamos também a utilização de notação prescritiva (clusters) e descritiva (últimas notas no grave).

\footnotetext{
16 "é todo fenômeno ou evento sonoro percebido como um todo coerente e entendido em uma escuta reduzida voltada ao som em si, isto é, independente de sua proveniência ou significação" (CHION, 1983, p. 34)

17 No caso dessa peça o vídeo já contém a partitura. Dessa forma, nos referenciamos à peça a partir desse ponto da seguinte forma: O primeiro número (X") representa o segundo que aparece anotado na partitura (equivalente ao compasso). O segundo número (video $\mathrm{X}: \mathrm{X}$ ) representa a minutagem na qual $\mathrm{O}$ excerto pode ser escutado no YouTube.
} 


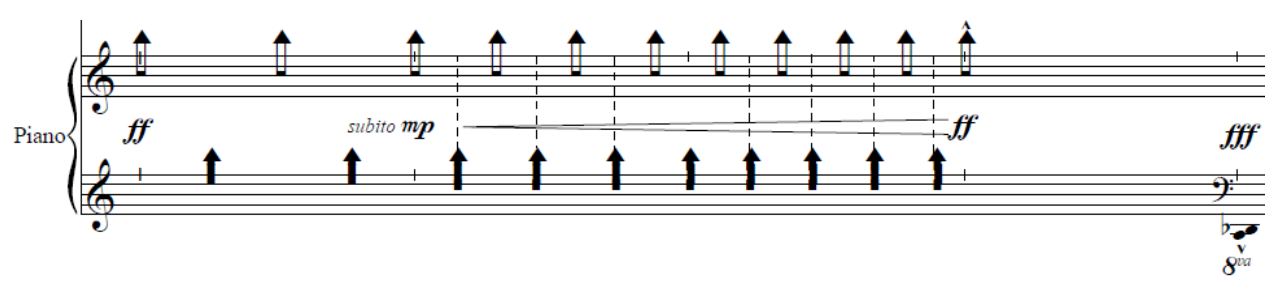

Fig. 7: (85" - Vídeo 2:10)

Na figura 8 observamos mais um exemplo de notação prescritiva em que as alturas são indefinidas e o mais importante é o gesto de subir e descer na harpa do piano. A primeira subida seguida de sua descida dura um segundo. Já a última dura sozinha um segundo e é mais ampla, isto é, atinge o registro mais agudo do piano.

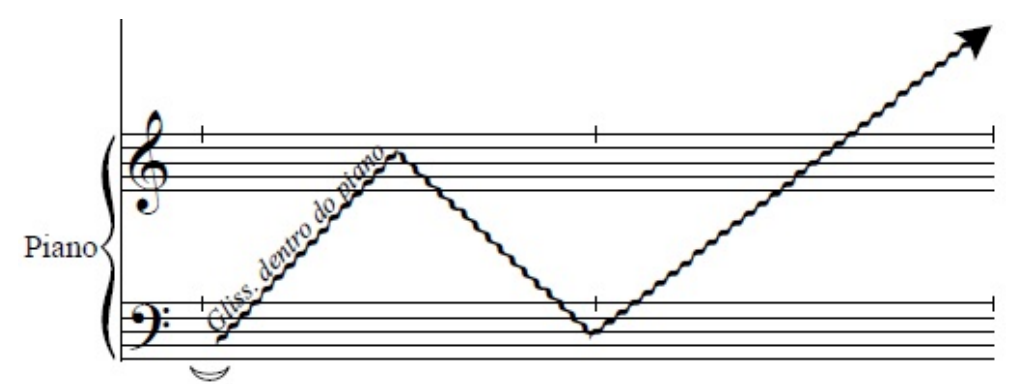

Fig. 8: (243" - Vídeo 4:48)

Para o recurso do Theremim já supracitado o compositor escolheu uma solução diferente da apresentada anteriormente (plano cartesiano). O parâmetro horizontal é controlado pelos números de 1 a 5 , representando a posição do mouse na tela de um computador (figura 9). O parâmetro vertical é controlado pela posição da linha/número no espaço em que estaria o pentagrama (que foi aumentado, eliminando também suas linhas intermediárias). Na figura 10, por exemplo, coloca-se o mouse na região 4 embaixo da tela e faz-se um gesto de elevação até o centro da tela (linha pontilhada). A figura 11 mostra-nos uma caixa de repetição que apresenta um gesto curvilíneo a ser realizado e repetido quantas 
vezes for necessário na posição que ele aparecer (nesse caso, parte inferior da tela entre números 4 e 5). A numeração dentro da caixa indica o tempo aproximado que deve durar cada movimento. Os casos abaixo aparecem na bula da peça e representam mais um caso de notação prescritiva em que o compositor indica o "como" fazer, mas não há como imaginar o resultado sonoro antes do movimento ser realizado no mouse em um computador 18 .

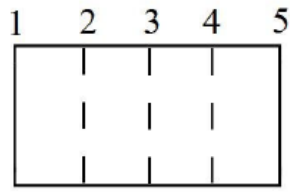

Fig. 9

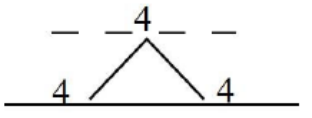

Fig. 10

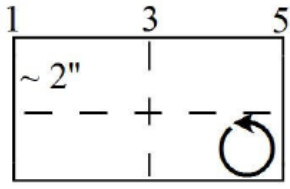

Fig. 11

\section{Considerações finais}

A discussão sobre o conceito de gesto que, segundo alguns teóricos ${ }^{19}$, é anterior à escrita musical e inspirou mesmo seus signos sendo, como diz Adorno (2001 apud CARVALHO 2005, p. 212) imagens de gestos -, levou-nos a investigar a relação do som com a notação. Essa relação se mostra conflituosa devido à limitação que o sistema de notação convencional apresenta no que se refere à notação de gestos musicais, por assim dizer, não convencionais - mas presentes hoje nos discursos musicais -, o que leva os compositores muitas vezes a buscarem ou mesmo a desenvolverem outras formas de grafia. Os autores deste artigo escolheram a escrita proporcional com elementos prescritivos para

18 Exemplos práticos de notação nesse sistema podem ser encontrados na partitura/vídeo da peça em questão de 0"-89" (video 0:45-2:15) e de 322"-377" (video 6:07-7:12)

19 Como os já citados Marie (1973); Carvalho (2005); e Kululuka (2001). 
ampliar o sistema de notação e chegar mais próximo do gesto mental que estava na gênese da criação das peças.

As duas peças apresentadas mostram alguns exemplos de como o gesto pode ser notado. Na obra Contaktus o conceito de gesto pôde ser observado em várias facetas como na escrita, no gesto do intérprete e no gesto da regência. Já Uma cor que desentorte o arco-íris, ao usar uma escrita proporcional balizada em segundos (e por não fazer uso da regência), demanda uma concentração maior do intérprete para a interpretação e realização gestual.

Os compositores encontraram soluções distintas para a escrita no que concerne à utilização do mesmo recurso disponível no SuperCollider (Theremim) em que a posição do mouse na tela do computador define a qualidade do som que o software gera. É importante salientar que não foram encontradas quaisquer referências de escrita para mouse, o que levou os compositores a criarem sua própria notação. O desafio foi como criar uma notação que representasse o movimento bidimensional ( $x$ e y) que o mouse percorre na tela do computador. Apesar de suas diferenças, os dois tipos de notação provaram-se igualmente suficientes para abarcar as demandas apresentadas, ficando para posterior investigação uma possível comparação entre eles.

\section{Referências}

BAIRRAL, Adeilton. Imbricações de um objeto cognitivo, visual, histórico e cultural. A prática luso-brasileira da notação musical antiga até o século XIX. Revista do Conservatório de Música, n. 3, 2010.

BARBOSA, Rogério V. Escuta/escritura: entre olho e ouvido a composição. Tese de Doutorado. Porto Alegre: IA/UFRGS, 2008.

CARVALHO, Mário Vieira de. A partitura como "Espírito sedimentado": em torno da teoria da interpretação de Adorno. In: R.A.D.P. F. Duarte, Virginia 
De Araújo; Kangussu, Imaculada Maria Guimarães (Orgs.) (Ed.). Theoria Aesthetica. Porto Alegre: escritos, p. 203-224, 2005.

CHION, Michel. Guide des objets sonores: Pierre Schaffer et la recherche musicale. Buchet/Chastel. Paris, 1983.

FERNEYHOUGH, Brian. Form-Figure-Style: an intermediate assessment. In: BOROS, James (ed.); TOOP, Richard (ed.). Collected writings. Amsterdam: Harwood Academic Publishers, 1995a. P. 21-28.

FORNARI, José. Da Assinatura Gestual à Expressividade Musical. Cadernos de Informática, v. 8, n. 2, p. 34-44, 2012.

HATTEN, Robert S. Interpreting musical gestures, topics, and tropes: Mozart, Beethoven, Schubert. Indiana University Press, 2004.

KULULUKA, Apollinaire Anakesa. Du fait Gestuel à l'empreinte sonore. Cahiers de musiques traditionnelles (2001): 221-236.

MARIE, Jean-Étienne. Sur quelques problèmes de notation. Musique en jeu, v. 13, p. 42-43, 1973.

MARINI, G. D. \& TOFFOLO, R. B. G. O Tratado dos objetos musicais de Pierre Schaeffer revisitado pela fenomenologia de M. Merleau-Ponty. In: IV Encontro de Pesquisa em Música, 2009. Maringá. Anais do IV Encontro de Pesquisa em Música. Maringá: Universidade Estadual de Maringá, 2009.

MIRANDA, P. A.; BARREIRO, D. L. Performer e meios eletrônicos: aspectos da interatividade na música eletroacústica mista. In: Horizonte Científico, v.5(2), 2011 , p. 1-26.

MORGAN, Robert P. Anthology of twentieth-century music. New York. Norton, 1992.

SOUZA, André. Ação e Significação: Em busca de uma definição de gesto musical. Dissertação de Mestrado, Instituto de Artes, Universidade Estadual Paulista (IA-UNESP), São Paulo, 2004. 
WISHART, Trevor. On Sonic Art, edited by Simon Emmerson. Amsterdam: Harwood, 1996.

ZAGONEL, Bernadete. O que é gesto musical. Brasiliense, 1992.

ZAMPRONHA, Edson S. Notação, representação e composição: um novo paradigma da escritura musical. Annablume, 2000. 